\title{
Tracing the Sources and Microbial \\ Degradation of PCBs in Field Sediments by a Multiple-line-of- evidence Approach
}

\author{
Chenchen HuAng ${ }^{1,2}$, YANHONG ZENG ${ }^{1 *}$, XiAOJUN
} LUO $^{1}$ AND BIXIAN MAI ${ }^{1}$

${ }^{1}$ State Key Laboratory of Organic Geochemistry, Guangzhou Institute of Geochemistry, Chinese Academy of Sciences, Guangzhou 510640, China (*correspondence:zengyh@gig.ac.cn)

${ }^{2}$ University of Chinese Academy of Sciences, Beijing, 100049, China (huangchenchen@gig.ac.cn, luoxiaoj@gig.ac.cn, nancymai@gig.ac.cn)

A multiple-line-of-evidence approach including quantification, enantiomer analysis, microbial community analysis, and compound-specific isotope analysis was used to investigate the fate of polychlorinated biphenyls (PCBs) in sediment cores.

The difference in the maximum PCB concentrations were in accordance with the significant difference in $\delta^{13} \mathrm{C}$ values strongly indicated two different $\mathrm{PCB}$ inputs at sites $1 / 2$ and 3. Negative correlations between the variation in chlorine per biphenyl (CPB) and Log Dhe/TPCB (Log Dehalococcoides-specific 16S rRNA gene/total molar concentration of PCBs) at different core depths were observed (Figure 1). Nonracemic compositions and pronounced stable carbon isotope fractionation $\left(\Delta \delta^{13} \mathrm{C}>1 \%\right.$ ) of PCB congeners were detected in sediment cores. Most PCB congeners showed ${ }^{13} \mathrm{C}$ enrichment from the surface to the bottom layer (Figure 1). The above findings indicated that strengthened PCB degradation occurred with increasing core depth and that Dehalococcoides spp. likely participated in PCB degradation in these sediments.

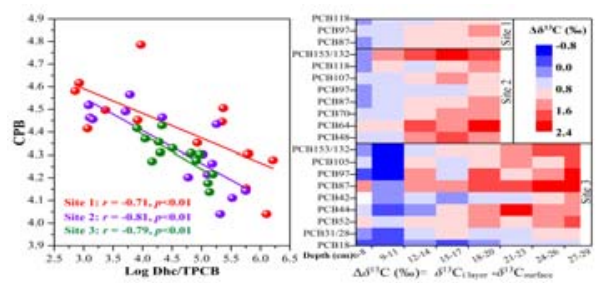

Figure 1: The correlation between CPB and Log Dhe/TPCB and the variation of $\delta^{13} \mathrm{C}$ values $\left(\Delta \delta^{13} \mathrm{C}\right)$ of individual $\mathrm{PCB}$ congeners in each interval relative to that in the surface (1-5 $\mathrm{cm})$ at the three sampling sites 